ISSN: 2162-3104 Print/ ISSN: 2166-3750 Online

Volume 8, Issue 2 (2018), pp. 677-695

(C) Journal of International Students

http://jistudents.org/

doi: 10.5281/zenodo. 1250370

\title{
International Counseling Students' Perception of Ethics
}

\author{
Mehmet A. Karaman \\ Kilis 7 Aralık University, Turkey \\ Michael K. Schmit \\ University of North Texas, USA \\ Ihsan C. Ulus \\ Bartin University, Turkey \\ Marvarene Oliver \\ Texas A\&M University- Corpus Christi, USA
}

\begin{abstract}
International counseling students' (ICS) perceptions regarding ethical counseling practice and education in the United States were examined using an online survey. The research sample consisted of ICSs who were enrolled in counseling programs throughout the United States. Findings indicated that even though ICSs came from different cultures with different ethical values, they were well aware of the different codes of ethics, reported engaging in ethical behaviors, and adapted themselves to the U.S. culture and education system. The results of this study may help counselor educators and counseling programs to promote and understand international students' ethical behaviors from a diverse and multicultural standpoint.
\end{abstract}

Keywords: international counseling students, ethical values, ethical behaviors, counselor education, codes of ethics 
International students represent almost $5 \%$ of the U.S. higher education population. More international students come to the United States to study than to any other country in the world (Institute of International Education [IIE], 2016). The number of post-secondary students willing to study abroad increases yearly for a variety of reasons. In a survey conducted by the British Council on student decision making, the primary motivation behind international students' desire to study in the United States. was career improvement (Morgan, 2010). According to the IIE's (2016) annual report, $1,043,839$ international students were enrolled in universities and colleges during the 2015-2016 academic year, an increase of nearly 70,000 over the previous year. Based on the academic level trends, approximately $37 \%$ of students are enrolled in graduate programs, where all counseling programs in the United States are housed. The specific numbers of international students who are enrolled in counseling programs is vague at best. While counseling programs have traditionally been housed in colleges of education in the United States, this is not always the case. No inferences about enrollment of international students in counseling can be made from data available through IIE.

In addition to the lack of specific information about international counseling students (ICSs) through IIE, there was no information available at the time of this study through the Council for Accreditation of Counseling and Related Educational Programs (CACREP) regarding international student enrollment. CACREP began publishing annual reports in 2012 which include statistical information about faculty and student demographics as well as numbers of accredited programs. A majority of institutions that house CACREP-accredited programs have more than one counseling program area (e.g., clinical mental health, school counseling). For example, in 2015 there were 84 CACREP-accredited counseling programs in 312 institutions (CACREP, 2015). Demographic information reported specify nine ethnicities/race groups (i.e., African American/Black, American Indian/Native Alaskan, Asian American, Caucasian/White, Hispanic/Latino, Native Hawaiian/Pacific Islander, Multiracial, NonResident Alien, and Other/Undisclosed); however, this report format does not provide information about international student status. Non-resident aliens might include international students, but there are international students who have resident-alien status. There may be international students who describe themselves as one of the other nine specified groups. In addition, these numbers only account for CACREP-accredited programs. 
Thus, it is difficult to know exactly how many ICSs are actually studying in the United States at any given time. Research relevant to international students who study counseling, whether at the master's or doctoral level, is limited (Lau \& Ng, 2012).

Moving from one country to another, especially with disparate cultural values and beliefs, may require international students to make difficult adjustments to the host country's culture, educational system, and way of living. International students bring their own cultural beliefs, morals, behaviors, and values when they come to study in the United States. These students add diversity to a college or university, enrich the understanding of other students on campus, and contribute to the economy (Carr, Koyama, \& Thiagarajan, 2003; National Association of Foreign Student Advisers, 2013; Ritter, 2016). Furthermore, international students can serve as ambassadors, bridging the differences between U.S. culture and their culture of origin. For instance, $\mathrm{Ng}$ (2006a) reported that $83.3 \%$ of counselor educators who worked with ICSs indicated that "working with ICSs had positively impacted me personally and professionally" (p. 11). However, international student characteristics, morals, values, and behaviors often differ from U.S. cultural norms, which represents Western cultural values and characteristics. For example, in the study by $\mathrm{Ng}$ (2006a), counselor educators rated ICSs from non-Western cultures as having more identified concerns (e.g., cultural adjustment problems, social and relational problems with peers, conflicts with Western understanding of and approaches to treating mental health) than domestic students. International students who study counseling in the United States may remain in the United States or may return to their home countries to practice and/or teach. How these individuals perceive ethics and gatekeeping, as well as how their perceptions impact their practice, is critical. Considering previous research and the lack of attention on ICSs' professional development, in the current study, we explored how ICSs' cultures of origin impact their ethical perceptions and ethics education in the United States.

\section{CODES OF ETHICS AND INTERNATIONAL STUDENTS}

Ethics can be understood as the collective values and moral principles that are inherent in a body of individuals. Codes of ethics are guidelines that establish normative practices and expectations and help to govern a profession (Francis \& Dugger, 2014). Within the profession of counseling in 
the United States, the embodiment of those collective values and morals are represented by the ACA Code of Ethics (American Counseling Association [ACA], 2014). The ACA Code of Ethics (2014) supports unity, community, and growth of the profession. However, this embodiment also may create conflicts between the counselor's personal values and the profession's collective values (Francis \& Dugger, 2014). This phenomenon is best represented in recent court cases such as Keeton v. Anderson-Wiley (2011) and Ward v. Wilbanks (2010), both of which have been viewed as reflecting counseling graduate students' discrimination against clients based on sexual orientation. In the first case, a student repeatedly expressed a desire to avoid LGBTQ clients and students and to subject them to conversion therapy. In the second case, a student refused to see a client because of the client's sexual orientation. Both cases are examples of how counselors-in-training's religious beliefs might impact their practice of counseling and ultimately the profession (Herlihy, Hermann, \& Greden, 2014). Both students in these cases were domestic students and both had their views of the Bible's teachings.

Despite increasing attention on diversity and numbers of International counseling students who include multicultural and diverse backgrounds, little attention has been given to international students and how they perceive the ACA Code of Ethics, ethical dilemmas, and ethical decision-making models commonly taught in U.S. counseling programs. If conflicts arise within the counselor who is identified as part of the dominant culture, it seems reasonable to assume that conflicts also occur in counselors who are international students. Ng and Smith (2009) stated that if ICSs want to be effective, they need to learn how to examine critically the fundamentals of Western-based theories in order to apply them in a culturally sensitive manner. The same may be assumed about the importance of critically examining fundamentals of Western-based ethical thought and codes.

Although CACREP, the National Board for Certified Counselors (NBCC), and professional counseling organizations (e.g., ACA) require ethics training in counseling programs' curricula, there is no standardized method for providing education in ethics (Tsai, 2013). The lack of consistent training methods can confuse ICSs when specific barriers (e.g., English language skills, cultural differences, experience of discrimination) are taken into account, especially for ICSs who are at the beginning of their training. Whether ICSs remain within the U.S. or return to their home countries to 
practice or teach, it behooves both the profession and ICSs that clarity about the role of counseling ethics in the U.S. and abroad be better understood in order to better promote and facilitate multiculturally competent discussions around ethics.

Examining ICSs' perceptions about ethics as taught or practiced in the United States is important. However, there is a dearth of research regarding this topic or about the challenges ICSs may face as they adapt to U.S. ethical codes and practice. Thus, the purpose of this study is to understand ICSs' thoughts and beliefs related to codes of ethics and ethical behaviors, and the influence of their original culture on their ethical decision-making process. To accomplish this task, a single research question was explored: How do international students' cultures of origin influence their perceptions of ethical practice and ethics education in the United States?

\section{RESEARCH METHOD}

A descriptive-exploratory survey research design was utilized to capture ICSs' perceptions of ethics. A descriptive survey design relies on structured questions that categorize participants' responses which can be analyzed using quantitative statistical procedures (e.g., descriptive statistics, t-test); an exploratory survey design traditionally take the form of open-ended questions which can be analyzed using qualitative procedures (e.g., open and axial coding) to obtain a richer understanding of a phenomenon or discovery of new phenomena (Pinsonneault \& Kraemer, 1993). Given our single research question, a descriptive-exploratory survey research design seemed appropriate in guiding our process of developing a deeper understanding of ICSs' perceptions of ethics.

\section{Procedures}

Upon receiving institutional review board approval, we utilized emails, and online postings to recruit students via listservs (i.e., Counselor Education and Supervision Network [CESNET], Counseling Graduate Students [COUNSGRAD]) and social media websites (i.e., ACA International Counseling Interest Network, Counseling Students) to recruit ICS participation in this investigation. Each method of solicitation included a brief description of the study and its purpose. Given the investigative nature of our survey and the unique population under inquiry, we targeted as 
many respondents as possible in order to obtain a comprehensive amount of data. Thus, the survey link was sent out three times within a two-week period. If respondents agreed to participate, they were asked to click on a link, included in each method of solicitation, directing them to a survey on Qualtrics (online survey software platform). Participants were provided an informed consent notice indicating the voluntary nature of the study, the absence of compensation, statement that data received were anonymous to the researchers, and the survey to be completed.

\section{Participants}

We targeted ICSs of U.S. institutions, irrespective of whether those institutions were public or private. A total of 38 respondents participated to the online survey. Of the 38 participants, 21 (55.3\%) completed the survey in its entirety. The mean age of the participants was 29.76 years $(\mathrm{SD}=5.08$; range, 24-46 years). Our sample consisted of 10 women (44\%) and 11 men $(56 \%)$. As for the nationalities of participants, $38.1 \%$ were Turkish $(\mathrm{n}=8)$, 9.5\% were Jordanian $(n=2), 9.5 \%$ were Japanese $(n=2), 9.5 \%$ were Kurdish $(\mathrm{n}=2), 9.5 \%$ were Indian $(\mathrm{n}=2), 9.5 \%$ were Chinese $(\mathrm{n}=2), 4.7 \%$ were South African $(n=1), 4.7 \%$ were Canadian $(n=1)$, and $4.7 \%$ were Greek $(\mathrm{n}=1)$.

Seventeen participants (81\%) were doctoral-level and four participants (19\%) were master's-level students; most were enrolled in either counselor education or educational psychology programs. Four of the 21 participants were vague in their reporting or failed to identify a specific area of study. Participants reported the countries they obtained their bachelor's degrees as United States $(n=2,9.5 \%)$, England $(n=2,9.5 \%)$, and home countries $(\mathrm{n}=17,81 \%)$. For their master's degree, 16 participants (76\%) earned their degrees in the UnitedStates while five participants $(24 \%)$ earned their degrees in their home countries. Additionally, $68 \%(n=14)$ of respondents indicated that they had previously taken an ethics course during their bachelor's or graduate program. Even though the majority had formal education in ethics, $27 \%(n=6)$ of respondents reported that they often debated about whether their actions and/or behavior were ethical. Eighteen percent $(n=4)$ of respondents always felt this way, while $23 \%(n=5)$ of participants responded ambiguously (i.e., did not indicate if they felt this way or not). 


\section{Measure}

Participants were asked to complete two sections of the survey: (a) a demographic information sheet and (b) an Ethical Perceptions and Values Questionnaire, which was created by the authors (see Appendix A). The demographic information sheet consisted of 10 questions related to participants' age, biological sex, nationality, education status, country where bachelor's and master's degree was obtained, counseling program emphasis, participation in an English as a second language course, participation in an extra English course during education in the United States, attendance in an ethics course, and scholarship and assistantship status.

The second section of the survey included 12 items using a 5-point Likert-type scale $(1=$ strongly disagree, $2=$ disagree, $3=$ neither agree, nor disagree, $4=$ agree, and $5=$ strongly agree) and five open-ended questions designed to elicit ICSs' perceptions of ethics in relation to the culture, level of education, purposes of counseling ethics; ethical decision making models to use when faced with an ethical dilemma, and perception of one's own ethical behavior. This instrument created by the authors since there was not an instrument in the field measuring the ethical behaviors of counselor-intrainings. The Cronbach's alpha reliability for the scores on the 12 Likerttype survey items portion was .67 for the sample under investigation. Likerttype and open-ended survey questions were developed by the first, second, and third authors. The fourth author, a proficient qualitative researcher, served as an expert in item development and provided critical feedback through a reflective process.

\section{RESULTS}

First, we present the results of the 12 Likert-type survey items based on the following categories: (a) ethics in education and practice and (b) ethics and culture. Next, we present response patterns (similarities and differences) from four of the five open-ended survey items. The fifth open-ended survey item is presented last, based on emergent themes developed using open coding procedures.

\section{Responses to Likert-type Survey Items}

Ethics in education and practice. All but one participant believed that ethics courses were necessary in counselor education programs. Twelve participants $(57 \%)$ perceived that LPCs are held to a higher ethical standard 
when compared to graduate counseling students. However, five participants $(23.8 \%)$ disagreed and four $(19.05 \%)$ were neutral. Despite this divergence in responses, $90 \%$ of participants considered themselves to be ethical and the majority of respondents $(86 \%)$ reported that their decisions were based on codes of ethics, laws, and other guidelines. Twelve participants (57\%) disagreed with the statement that ethical decision-making models are unnecessary while two participants $(10 \%)$ agreed. The remaining seven (33\%) neither agreed nor disagreed.

\section{Ethics and Culture}

When asked about being multiculturally competent, $90 \%$ of participants indicated that they perceived themselves as such. All but two participants understood that they were bound to ethical standards of the host county, even if they were to return to their country of residency upon graduation. When faced with an ethical dilemma, 81\% $(\mathrm{n}=17)$ of respondents reported that others should not make exceptions for their judgments just because they are international students; one person expressed the exact opposite while the remaining three were unsure. In response to understandability and language of codes of ethics, the majority of respondents $(71 \%)$ indicated that the language was easy to fairly easy to understand, with two respondents $(10 \%)$ indicating some confusion with the interpretation of ethical codes. When asked specific questions regarding participants' values and belief systems, a majority of respondents $(67 \%)$ indicated that referring a client with dissimilar beliefs or values from theirs is inappropriate and that, irrespective of the cultural implications of gifts, the monetary value of a gift is important to consider when accepting a gift $(90 \%)$.

\section{Responses to Open-ended Survey Items}

Next, four open-ended survey questions were explored. When asked which codes of ethics they were aware of, all respondents reported that they were familiar with the ACA Code of Ethics (2014). However, some respondents reported an awareness of additional codes of ethics, such as the Ethical Principles of Psychologists and Code of Conduct (American Psychological Association [APA], 2010) or codes of ethics specific to divisions in the ACA. All participants reported using ethical decisionmaking models when faced with an ethical dilemma. Several models were 
named; however, the most frequently cited model used was the Practitioner's Guide to Ethical Decision Making (Forester-Miller \& Davis, 1996).

Participants were also asked to identify three purposes of counseling ethics. A majority of respondents replied that counseling ethics serve to ensure the welfare of clients, maintain respect and credibility of the profession, and provide protection to the counselor as well as the profession. One respondent indicated that counseling ethics defines the current ideologies of the counseling profession, while two participants offered that codes of ethics provide a sense of pride and offer standardization of counseling practices.

\section{Coded Open-Ended Survey Item: Influence of Cultural Values}

One open-ended survey item was coded qualitatively using open coding to understand ICSs' perceptions of counseling ethics. The question asked was: In what ways do your cultural values influence how you determine what is right and what is wrong? Emergent themes arising from participants' voices were: (a) collectivism versus individualism, (b) decision to act as if, and (c) conscious awareness.

\section{Collectivism Versus Individualism}

One salient theme voiced by ICSs was the influence of their collectivist cultures, which informed their cognitive and behavioral processes in determining what was just or unjust. Given that a majority of participants originated from countries that value actions or behaviors that benefit the greater good, it is not surprising that the theme of collectivism versus individualism was consistently expressed throughout responses. For instance, R19, a doctoral student from China, stated, "Definitely, my Asian collectivism view of seeing the world influence[s] what is right and wrong." Similarly, R10, a doctoral student from Turkey, indicated that "in the culture that I come from, individualism is not the main concern .... Collectivist concerns and interest come before individual interests." R13, a doctoral student from Canada, stated, "Compared to the US [United States], Canada is more socialistic.... Sometimes I believe that individual 'freedoms' practiced by Americans are taken to such extremes and should be limited...." However, not every individual verbalized this collectivist perspective, and in fact, R2, a doctoral student from Japan, went as far to say that "it does not much influence how I determine what is right or wrong, 
since my ethical decision-making process is very much as what ACA ethics code states."

\section{Decision To Act As If}

Another notable theme that emerged was participants' decisions to act as if their cultural values were not a factor in the decision-making process. Despite the ICSs' cultural backgrounds, they felt responsible to set aside their own personal values and beliefs, and even culture if need be, in order to ensure the welfare of the clients they served. This theme was most clearly stated by R4, a doctoral student from Turkey: "My cultural values and my faith do influence my determination.... However, in my professional life, I am bound more with this ethics of my profession than my culture and faith." Similarly, R18, a master's student from South Africa, voiced, "I try to avoid my own cultural values because this is a different culture and if I use my own cultural values things don't work."

Despite the prominence of this theme, not every participant agreed with the notion of acting as if. A few participants indicated that their cultural values did in fact impact their decisions about whether something was right or wrong. They relied upon personal moral principles rather than codes of ethics in deciding if something was just or unjust. For example, R7, doctoral student, from Turkey, noted that "because I am an international and not citizen [SIC], I would like multicultural issues to be considered and respected. Otherwise, I freely take the side of freedom, human rights, and democratic values."

\section{Conscious Awareness}

It was quite clear that ICSs were well aware of how various ethical guidelines informed their determination of what is right and what is wrong but also that they were consciously aware of the impact of their own cultures. A majority of participants indicated that they were aware of how their cultural values influenced their decision-making process. For example, R12, EdD student, from Turkey, stated, "I have lived in many cultures. Therefore, my cultural values give me chances to respect and empathize quickly [with] other cultures." Similarly, R16, PhD student, from India, detailed an awareness of cultural values and its impact on particular topics, "especially with regard to family, relationships, marriage, sexuality, etc." Interestingly, R21, MA student, from England, recognized how cultural values impact his/her personal determination of what is right and what is 
wrong may be at least in some ways unconscious, and stated that cultural values had impact ". . . in ways that are mainly subconscious, as they have been inside me since I was a kid."

\section{DISCUSSION}

The current study investigated how ICSs' cultures of origin impact their ethical perceptions as well as perception of ethics education in the U.S. Findings from this study indicated that collectivism versus individualism, decision to act as if, and conscious awareness are the three crucial emergent themes derives from individuals' cultural background.

Individualistic cultures as a whole are more likely to value autonomy and an individual perspective. In terms of collectivistic cultures, however, society is more influential in people's lives, and people identify themselves through their relationships with people around them (McCarthy, 2005). While an individualistic approach appears to be predominant in Westernized countries (e.g. the United States., Australia), collectivism appears to be more dominant in Eastern cultures (Nelson \& Fivush, 2004). A majority of participants in this study came from collectivistic cultures and noted that collectivism had an impact on their understanding of what is just or unjust.

The most robust and reassuring finding of this online survey research was that ICSs were all familiar with the ACA Code of Ethics (2014) as well as other codes of ethics (e.g., ASCA, APA). International counseling students pointed out that the guidelines of ethical codes and ethical principles are crucial and necessary. They use these ethical codes and principles to ensure the welfare of clients, support their clients' rights, and build an appropriate therapeutic relationship. While some ICSs may decide to stay in the U.S., others will return to their home countries to work in different counseling settings after completing their counseling degrees. Interestingly, a majority of ICSs indicated that they would continue to utilize American-based ethical codes if they return to their home countries even though students who return to their country of origin are not necessarily bound by any specific rules or regulations requiring them to continue this practice. One possible explanation for this may be the impact counselor education programs have on ICSs' professional identity development. Students enrolled in programs with counselor educators who possess a strong professional identity are more likely to develop one 
themselves (Meany-Walen et al., 2013; Willis-O'Connor, Landine, \& Domene, 2016).

The ACA Code of Ethics (2014) provides ethical standards and guidelines for counseling professionals about how to practice, research, collaborate with other professionals, and resolve an ethical issue properly. Even though the professional ethical codes and guidelines are crucial, they may not be adequate in providing assistance to help ICSs to resolve some ethical issues (Sperry, 2007; Tsai, 2013). In this respect, it can be important for ICSs to understand and internalize a decision-making model when they face an ethical dilemma (Remley \& Herlihy, 2014). In parallel with this, half of ICSs acknowledged that ethical decision-making models are necessary to resolve an ethical dilemma when they practice; however, fully one third indicated neither agreed nor disagreed with the importance of using such models. The rationale behind ethical decision-making models is to help counseling professionals develop wide analytic approaches to resolving ethical dilemmas. In addition, these models provide conceptual frameworks and collaborative processes for counselors to use as they make decisions in their practice (Sperry, 2007).

The results of this study support the importance of incorporating standards of ethical practice and ethical decision-making models into the curriculum of counselor education programs (Levitt, Hartwig-Moorhead, \& Ebrary, 2013; Vergés, 2010). In spite of the fact that professional counseling orientation and ethical practice is one of eight core areas that must be represented in the curricula in CACREP-accredited counseling programs (CACREP, 2016), research indicates there is a lack of coverage of ethical practice in some countries' counseling training programs, including those in Turkey (Sivis-Cetinkaya, 2015), China (Deng, et al., 2016), and Iran (Yadegarfard \& Bahramabadian, 2014). Incorporation of ethics education into the curriculum is helpful to both international and domestic counseling students (Tsai, 2013), despite the fact that ICSs may return to their countries of origin and have to adapt ethical decision-making to their home country. However, in the re-adaptation process of ethical codes from the host country to home country, ICSs may face challenges because ethical codes are fundamentally constructed on the Western cultural context and its assumptions (Gerstein et al., 2009).

In contrast to some literature that notes that international counseling students may be more culturally encapsulated and at risk of being prejudiced or enforcing their values or perceptions on their clients (Ahmed, Wilson, 
Henriksen, \& Jones, 2011; Ng, 2006b), findings of the current study indicated that ICSs viewed themselves as possessing multicultural counseling competencies, including the awareness of one's culture, multicultural counseling skills, and knowledge about different cultures in the context of the counseling profession around the issue of ethics. A majority of participants in this study noted that their cultural background, values, and belief system did not influence their therapeutic relationship and environment with their clients. Furthermore, some participants noted that having a broader perspective positively affected their ability to form a therapeutic relationship as well as their ethical-decision making procedures. Results of this study provide a deeper understanding of ICSs' perceptions of ethics and the way they practice ethically. It is critical to understand how ICSs understand ethical principles taught in the United States as well as how they think about ethical decision-making and their own cultures in order to better prepare ICSs for future practice. The results of this survey study provide useful information for counselor educators, counselors, counseling and international counseling students, and future counselors in regard to the international context.

Counselor educators play a vital role in the ethical development process of their students. This is no less true for their ICSs than for domestic students. Understanding how ICSs perceive ethical codes and ethical practice as well as ethical decision-making models may allow counselor educators to more effectively present critical information about ethics as well as to more effectively assess and address possible areas of difficulty for ICSs. Results of this study may also provide additional context about international students that is useful for facilitating discussion about ethical dilemmas that may better inform domestic students about their own contexts. For example, while multicultural courses may consider the differences in collectivistic and individualistic cultures, neither domestic nor international students may understand the impact of such differences on ethical codes and ethical thinking. In fact, domestic students and faculty may be unaware that, in some countries, there is no agreed-upon set of ethical considerations and that general values of the culture rather than systematized ethical thought guide decision-making. 


\section{RECOMMENDATIONS AND LIMITATIONS}

The essential aim of this study was to explore the ethical perceptions of ICSs who were enrolled in U.S. counselor training programs. Research indicate that sojourners may deal with variety of problems such as culture shock, homesickness, social problems, isolation, lack of support system and finances issues which begin from leaving home culture and entering to the host culture (Lau \& Ng, 2012). Despite the fact that ICSs came from different cultural backgrounds, results of this study provide positive indicators of participants' adaptation to and adjustment around ethical thought as taught in their U.S. counseling programs.

Professional ethical codes reflect values of the dominant culture and are based in large part on Western philosophical theories of ethical obligation (Ford, 2006). International counseling students, particularly those from non- or less-Westernized countries of origin, bring into their counseling programs values, morals, and standards of behavior that may be based on significantly different underlying philosophical foundations from those that underlie codes of ethics in the mental health disciplines in the United States. These students must adapt to normative ethical thinking and practices in the United States during their programs, even if they intend to return to their countries of origin to practice or teach. Both domestic and international counseling students may benefit from in-depth discussion of foundational values of ethical thinking, including discussion of how foundational values vary across cultures

There are a few limitations of this study that we would like to highlight. First, the largest percentage of participants in the study selfidentified as Turkish. A sample with wider variety of countries of origin may have produced richer results. Second, the number of respondents is fairly small and a response rate cannot be determined due to the limited data available on ICSs; thus, results should be understood within the context of the limited sample under investigation. Third, a Cronbach's alpha coefficient of .67 indicates uncertain internal consistency for the scores (Kline, 2000). Last, the 12-item instrument developed by the authors is not a validated measure. 


\section{CONCLUSION}

Additional research is explicitly needed in this area. While the current study provides initial information about how ICS' experience ethical thinking and education in the United States, including findings that participants have adopted U.S. ideas about counseling ethics, more research is needed in order to incorporate understanding of non-Western values and beliefs into the teaching of ethics. Certainly, research regarding whether and how Western ideas about ethics may be adapted to other countries is worthy of investigation. Future studies that examine possible differences among ICSs from different countries may be beneficial in fostering increased multicultural understanding. Studies that include both domestic and international counseling students' perceptions of ethical codes may provide counselor educators and supervisors with useful ways to strengthen ethical reasoning. Additional information regarding alterations that are perceived as necessary for those who return to their home countries is also worthy of investigation.

\section{REFERENCES}

American Counseling Association. (2014). ACA code of ethics. Alexandria, VA: Author.

American Psychological Association (2010). Ethical Principles of Psychologists and Code of Conduct. Washington, DC: Author.

Ahmed, S., Wilson, K. B., Henriksen, R. C., \& Jones, J. W. (2011). What does it mean to be a culturally-competent counselor? Journal for Social Action in Counseling \& Psychology, 3, 17-28. doi: 10.1037/e628592012-172

Carr, J. L., Koyama, M., \& Thiagarajan, M. (2003). A women's support group for Asian international students. Journal of American College Health, 52, 131134. doi:10.1080/07448480309595735

Council for Accreditation of Counseling and Related Educational Programs. (2015). Annual report. Retrieved from http://issuu.com/cacrep/docs/ cacrep_2015annualreport_final_digit

Council for Accreditation of Counseling and Related Educational Programs. (2016). CACREP Standards. Retrieved from http://www.cacrep.org/news/2016cacrep-standards-available-in-pdf-format/

Deng, J., Qian, M., Gan, Y., Hu, S.,Gao, J., Huang, Z., \& Zhang, L. (2016). Emerging practices of counseling and psychotherapy in China: Ethical dilemmas in dual relationships. Ethics \& Behavior, 26, 63-86. doi:10.1080/10508422.2014.978978 
Ford, G. G. (2006). Ethical reasoning for mental health professionals. Thousand Oaks, CA: Sage Publications, Inc.

Forester-Miller, H., \& Davis, T. E., (1996). A Practitioner's Guide to Ethical Decision Making. Alexandria, VA: American Counseling Association.

Francis, P. C., \& Dugger, S. M. (2014). Professionalism, ethics, and value-based conflicts in counseling: An introduction to the special section. Journal of Counseling \& Development, 92, 131-134. doi:10.1002/j. 15566676.2014.00138.x

Gerstein, L. H., Heppner, P. P., Aegisdottir, S., Leung, S. A., \& Norsworthy, K. L. (2009). International handbook of cross-cultural counseling: Cultural assumptions and practices worldwide (1st ed.). Los Angeles, CA: Sage.

Herlihy, B. J., Hermann, M. A., \& Greden, L. R. (2014). Legal and ethical implications of using religious beliefs as the basis for refusing to counsel certain clients. Journal of Counseling \& Development, 92, 148-153. doi:10.1002/j.1556-6676.2014.00142.x

Institute of International Education. (2016). Open doors 2016 fast facts. Retrieved from www.iie.org/ /media/Files/Corporate/Open-Doors/Fast-Facts/FastFacts-2016.pdf?la

Keeton v. Anderson-Wiley, 664 F.3d 865 (11th Cir. 2011).

Kline, P. (2000). The handbook of psychological testing (2nd ed.). London, UK: Routledge

Lau, J. \& Ng, K (2012). Effectiveness and relevance of training for international counseling graduates: A qualitative inquiry. International Journal for the Advancement of Counselling, 34, 87-105. doi: 10.1007/s10447-011-91282.

Levitt, D. H., Hartwig Moorhead, H. J., \& Ebrary, I. E. (2013). Values and ethics in counseling: Real-life ethical decision making (1st ed.). New York, NY: Routledge.

McCarthy, J. (2005). Individualism and collectivism: What do they have to do with counseling? Journal of Multicultural Counseling \& Development, 33, 108117. doi:10.1002/j.2161-1912.2005.tb00009.x

Meany-Walen, K. K., Carnes-Holt, K., Barrio Minton, C. A., Purswell, K., \& Pronchenko-Jain, Y. (2013). An exploration of counselors' professional leadership development. Journal of Counseling \& Development, 91, 206215. doi:10.1002/j.1556-6676.2013.00087.x

Morgan, J. (2010, September 10). What motivates international students? Times Higher Education. Retrieved from https://www.insidehighered. com/news $/ 2010 / 09 / 30 /$ foreign

National Association of Foreign Student Advisers. (2013). Explore International Education. http://www.nafsa.org/Explore_International_Education/For_The_Media/Pr 
ess_Releases_And_Statements/International_Students_Support_Job_Creati on_and_Contribute \$24_Billion_to_U_S_Economy/

Nelson, K. \& Fivush, R. (2004). The emergence of autobiographical memory: A social cultural developmental theory. Psychological Review, 111, 486-511. doi:10.1037/0033-295x.111.2.486

$\mathrm{Ng}, \mathrm{K}$. (2006a). Counselor educators' perceptions of and experiences with international students. International Journal for the Advancement of Counselling, 28, 1-19. doi:10.1007/s10447-005-8492-1.

$\mathrm{Ng}, \mathrm{K}$. (2006b). International students in CACREP-accredited counseling programs. Journal of Professional Counseling, Practice, Theory, \& Research, 34(1/2), 20-32.

Ng, K., \& Smith, S. D. (2009). Perceptions and experiences of international trainees in counseling and related programs. International Journal for the Advancement of Counselling, 31, 57-70. doi:10.1007/s10447-008-9068-7.

Pinsonneault, A., \& Kraemer, K. L. (1993). Survey research methodology in management information systems: An assessment. Journal of Management Information Systems, 10, 75. doi:10.1080/07421222.1993.11518001

Remley, B. \& Herlihy, T. P. (2014). Ethical, legal, and professional issues in counseling (4th ed.). Upper Saddle River, NJ: Prentice Hall.

Ritter, Z. S. (2016). International Students' Perceptions of Race and SocioEconomic Status in an American Higher Education Landscape. Journal of International Students, 6, 367-393.

Sivis-Cetinkaya, R. (2015). Ethical judgments of counselors: Results from a Turkish sample. Ethics \& Behavior, 25, 400-417. doi:10.1080/10508422.2014.941981

Sperry, L. (2007). The ethical and professional practice of counseling and psychotherapy. Boston: Pearson/Allyn and Bacon.

Tsai, Y. (2013). Ethics education and its influences on rehabilitation counseling master's students (Doctoral dissertation). Retrieved from Dissertations and Theses database. (UMI No. 3566714).

Vergés, A. (2010). Integrating contextual issues in ethical decision making. Ethics \& Behavior, 20, 497-507. doi:10.1080/10508422.2010.521451

Ward v. Wilbanks, 2010 WL 3026428 (E.D. Mich. July 26, 2010).

Willis-O'Connor, S., Landine, J., \& Domene, J. (2016). International students' perspectives of helpful and hindering factors in the initial stages of a therapeutic relationship. Canadian Journal of Counselling and Psychotherapy [Revue canadienne de counseling et de psychothérapie], 50, 379-400.

Yadegarfard, M., \& Bahramabadian, F. (2014). Sexual orientation and human rights in the ethics code of the psychology and counseling organization of the Islamic Republic of Iran (PCOIRI). Ethics \& Behavior, 24, 350-363. doi:10.1080/10508422.2013.845733 


\section{APPENDIX A}

\section{Demographic Questions}

1. What is your age?

2. What is your sex?

3. What is your nationality?

4. What is your education status?

5. Please list the country(ies) where you obtained your degrees?

6. Please identify your counseling program emphasis.

7. Did you attend any ESL (English as a Second Language) course before you started your education in the United States?

8. Did you take an extra English course during your education in the United States?

9. Have you ever taken any ethics course during your education?

10. Have you had an assistantship or scholarship from the program/university where you are currently studying?

Twelve Likert-type Survey Items Using a 5-point Likert-type Scale (1 = strongly disagree, 2 = disagree, $3=$ neither agree, nor disagree, $4=$ agree, and 5 = strongly agree)

1. My decisions are based in codes of ethics, laws, or other guidelines.

2. Licensed Professional Counselors are held to a higher ethical standards compared to counseling students.

3. The language of codes of ethics is confusing and difficult to interpret.

4. Counseling ethics are not important because when I return to my home county, I am not required to follow an American-based ethical code.

5. When I have faced an ethical dilemma, I believe others should make exceptions in their judgments of my decisions because I am an international student.

6. The language of codes of ethics is confusing and difficult to interpret.

7. Counseling education programs should teach ethics.

8. If the client's lifestyle and belief system violate my beliefs, I may refer the client/patient to another professional or dismiss him/her.

9. I have multicultural competence.

10. I may accept a gift from a client/patient without taking account the monetary value since I respect the client/patient.

11. I am an ethical person.

12. Ethical decision-making models are unnecessary to solve an ethical dilemma. 


\section{Open-Ended Questions}

1. How often do you debate whether your actions or behaviors cross the boundaries of what is ethical?

2. Which codes of ethics are you aware of?

3. Describe three important purposes of counseling ethics specifically for you.

4. What ethical decision making model do you use when faced with an ethical dilemma?

5. *In what ways do your cultural values influence how you determine what is right and what is wrong?

* Indicates that item was open coded.

MEHMET A. KARAMAN, $\mathrm{PhD}$, is an Assistant Professor of Psychological Counseling and Guidance. His research interests include instrument development and validation, achievement motivation, college counseling, and ethics in multicultural societies. Email: Mehmetkaraman@kilis.edu.tr

MICHAEL K. SCHMIT, PhD, is an Assistant Professor of Counseling. His research interests include counseling outcome research, integrated care treatment approaches, and quantitative research methodology. Michael.schmit@unt.edu

IHSAN C. ULUS, $\mathrm{PhD}$, is an Assistant Professor of Psychological Counseling and Guidance. His research interests include internationalization of counseling, counseling with international students, school counseling, and qualitative research methodology. Cagatayulus@gmail.com

MARVARENE OLIVER, PhD, is a Professor of Counseling. Her research interests include ethical and professional issues in counselor education and practice, supervision, pedagogy in counselor education and training, and bridging research and practice. Marvarene.oliver@tamucc.edu

Manuscript submitted: January 3, 2017

Manuscript revised: March 12, 2017 Accepted for publication: August 20, 2017 